
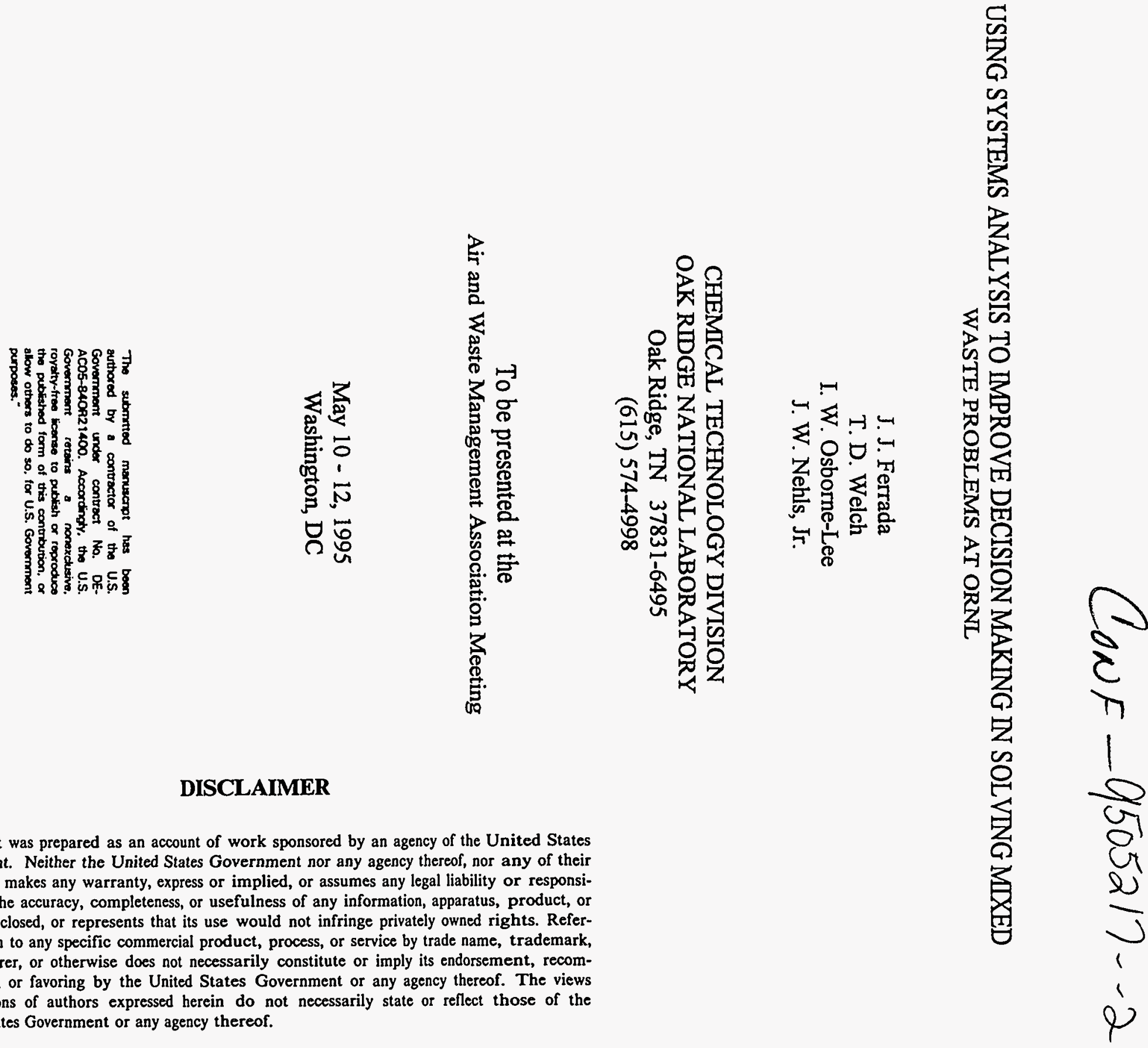

This report was prepared as an account of work sponsored by an agency of the United States Government. Neither the United States Government nor any agency thereof, nor any of their employees, makes any warranty, express or implied, or assumes any legal liability or responsibility for the accuracy, completeness, or usefulness of any information, apparatus, product, or process disclosed, or represents that its use would not infringe privately owned rights. Reference herein to any specific commercial product, process, or service by trade name, trademark, manufacturer, or otherwise does not necessarily constitute or imply its endorsement, recommendation, or favoring by the United States Government or any agency thereof. The views and opinions of authors expressed herein do not necessarily state or reflect those of the United States Government or any agency thereof. 


\section{DISCLAIMER}

Portions of this document may be illegible in electronic image products. Images are produced from the best available original document. 


\title{
Using Systems Analysis to Improve Decision Making in Solving Mixed Waste Problems at the Oak Ridge National Laboratory
}

\author{
J. J. Ferrada, T. D. Welch, I. W. Osborne-Lee, and J. W. Nehls, Jr. \\ Oak Ridge National Laboratory \\ 105 Mitchell Road, MS-6495 \\ Oak Ridge, Tennessee 37831
}

\begin{abstract}
Systems analysis methods and tools have been developed and applied to the problem of selecting treatment technologies for mixed wastes. The approach, which is based on decision analysis, process modeling, and process simulation with a tool developed in-house, provides a one-of-a-kind resource for waste treatment alternatives evaluation and has played a key role in developing mandated treatment plans for Oak Ridge Reservation mixed waste.
\end{abstract}

\section{INTRODUCTION}

The U.S. Department of Energy (DOE) reports a national cumulative inventory of mixed hazardous and radioactive low-level waste (MLLW) at DOE sites of about $1.93 \times 10^{8} \mathrm{~kg}$ (DOE 1993). Through 1992, about $6.2 \times 10^{7} \mathrm{~kg}$ of mixed wastes was stored on the Oak Ridge Reservation (ORR), and $2.5 \times 10^{7} \mathrm{~kg}$ of this was treated to meet land disposal restrictions (LDR). Environmental law requires that the hazardous components of mixed waste be treated before disposal. Although there are a variety of technologies for treating mixed wastes, finding the best, or even finding an acceptable treatment for some of these wastes is a challenging task. The Federal Facilities Compliance Act (FFCA) required DOE to provide site treatment plans on March 1995. The treatment plan had to identify the preferred treatment of both the existing inventory of mixed wastes and any future generation of mixed wastes and address specific issues set forth in the law. The plan had to spell out how, where, and when the waste will be treated and disposed.

To develop the treatment plan for the ORR mixed waste by the required date, a method of analysis for quickly and easily conducting trade-off studies and alternatives evaluations was needed. An evaluation of ORR management of mixed waste, including generation, storage, treatment, and disposal, indicated that a systems analysis was required, including development of automated analysis tools and integrated models. An integrated analysis approach was needed because of 1 ) the complexity of system interactions, 2) the diversity of alternatives to be studied, and 3) the variability and uncertainty of constraints. Many possible combinations of treatment and disposal options exist, each of which results in different costs, schedules, quality of waste form, risk to workers and the public, acceptability, etc. To select a treatment process for a given mixed waste, it must be known how effectively the process treats the waste, the costs to treat the wastes, and what level of risk the process poses. It is also desirable to consider "fuzzy" factors such as how well the technology is accepted by regulators and the public, the technical maturity of the technology, etc. Furthermore, it is critical to know how the availability of disposal options affects the choice of treatment technologies. The diverse waste categories and the variety of treatment alternatives further complicate the analysis.

The global systems analysis approach applied to the FFCA effort has also been used for the evaluation of alternatives for the mixed waste treatment facility (MWTF) recently proposed for the ORR. This approach has also been applied to the evaluation and comparison of appropriate waste treatment technology scenarios relevant to the out-of-state treatment issue with several evaluation criteria for two Portsmouth Gaseous Diffusion Plant (PORTS) waste streams. 


\section{SYSTEMS APPROACH}

A systems approach was taken to evaluate how potential treatment technologies might perform in the present and future waste management system in a timely and cost-effective manner. Beginning with an overview of the system, the components of the system that are of major importance are included in the analysis. Relationships between and among the major components are studied to identify principal interactions and specific areas within the system requiring more detailed study.

The objective of this systems analysis was to provide decision tools to help select safe, effective, environmentally sound, inexpensive, and acceptable (to regulators, governments, and the public) means of treating mixed wastes. The goal was to estimate how existing and potential technologies might best be integrated and deployed. The tight schedule for delivery of the treatment plan-March 1995-made it impossible to complete an exhaustive research, development, demonstration, and characterization effort before issuance of the plan.

An understanding of the demand for treatment, interim storage, and disposal capacity can be obtained with a top-level model of the system, provided that enough of the following information exists to predict material flows to and from system components:

1. generation

2. initial storage

3. treatment

4. post-treatment storage

5. transport

6. disposal

The waste generation and storage components are manageable, and information on quantities has already been reported under the FFCA. ${ }^{1}$ Waste characterization is more difficult, but this problem was tackled in a separate effort which provided data on waste stream characteristics for use in this study. The key and the most challenging component to elucidate is treatment.

It is clear that the methodology must elaborate a strategy that includes development of scenarios, process simulation, and integration of the analysis elements. Only then will the benefits of systems analysis become evident.

\section{Scenario-based Analysis}

The first step in this systems analysis approach is to study the significant factors that determine the possible waste treatment scenarios (see Fig. 1). These factors include waste inventory characteristics (e.g., quantity, the form-sludge, liquids, solids, etc. and contaminants); regulatory drivers (e.g., as the maximum contaminant level allowed in the processed waste, the time-constraints on treating the wastes, and the rules for disposal of treated wastes); system requirements (e.g., criticality concerns, safety, and transportation); and treatment and disposal technologies.

To perform the analysis, each scenario was represented by a set of independent process models linked together to form an overall model of each scenario. These models require data such as costing functions, transportation distances and requirements, and risk estimates. To model a scenario, the results from all process models must be integrated.

The scenarios for analysis were built by selecting a set of waste streams and combining these with appropriate treatment processes that could result in (a) acceptable discharges to the environment and (b) waste forms which meet the waste acceptance criteria (WACs) of the chosen waste disposal site. So that transportation costs and risks may be evaluated, the distances between waste storage sites, treatment locations, and disposal sites were included in the scenarios. Usually, only scenarios with common waste streams were compared with each other, although each scenario could be independently evaluated and scored.

Thus the methodology for building scenarios was as follows:

- Assemble combinations of

-Waste category, quantity, and location 
-Treatment types and location

-Disposal site with WACs

- Eliminate inappropriate combinations on the basis of

-Inappropriate treatment for waste type

- Inability to meet regulatory requirements/drivers

- Use remaining combinations as scenarios for systems analysis comparison of cost, safety, risk, and other performance measures.

The use of scenarios was chosen to arrive at a "best" set of treatment alternatives for mixed waste on the ORR. This choice was made as opposed to a multivariate optimization because of several important factors. A primary factor in this choice is the uncertainty in waste characterization and treatability. Also, there are fuzzy variables, such as public acceptance of a technology, equity issues in the final disposition of waste, and technology maturity. These factors make the formulation of an objective function difficult and are more amenable to a scenario-based approach. Furthermore, the goal in this study was not to find the optimal set of technologies, but to find a practicable set that reflects the objectives:

- Comply with the Resource Conservation and Recovery Act (RCRA) and other applicable regulations.

- Accelerate the schedule for technology development and demonstration and waste treatment and final disposition.

- Decrease the life-cycle costs of mixed waste treatment, storage, and disposal.

- Limit short-term and long-term risks associated with continued storage, treatment, and final disposition of the mixed wastes.

- Enhance the public acceptability of the mixed waste management program.

\section{Process Simulation}

A process simulation model is required to model the selected scenario. The process simulation model should have the following characteristics and capabilities. It should

- Consider generation, storage, treatment, and disposal of mixed waste.

- Be simple and not detailed, but down to unit operations level.

- Be readily modifiable in order to add or remove process components.

- Be easily used by novices.

- Provide material and energy balances with a minimum of detailed input.

- Provide information needed for cost and risk analyses and comparisons.

- Maintain consistency across technologies.

- Be capable of addressing major waste types or groups.

The modeling approach chosen addresses the diversity of waste streams to be treated and encompasses the range of preferred technologies. Detail in modeling was limited in order to be consistent with the degree of uncertainty in waste stream characteristics and the treatability for a given technology. The models were designed to be simple, yet able to capture the essential behavior of the process and produce needed measures of factors such as mass flows, risk, and cost. Model integration and the capability for rapid flow sheet building, which were also key objectives, are important advantages of our modeling approach.

Process models have been built using FLOW, a user-friendly process simulator developed at Oak Ridge National Laboratory (ORNL). FLOW is well suited to modeling waste treatment technologies. Its graphical user interface allows the user to rapidly build flowsheets that model a specific treatment technology or scenario. The user can quickly alter the various unit operations to study the effects of the changes on the treatment process. Each basic unit operation is represented by an icon. As will be explained later, complete flowsheets can also be represented by a single icon. This modeling environment allows the user to rapidly construct and evaluate many different flowsheets. FLOW produces the data, including mass flows and concentrations, for determining important process 
performance parameters such as volume reduction, secondary waste generation, and final contaminant concentrations of the wastes. In addition, FLOW calculates life-cycie costs and health risk to the worker and the nearby population.

Process Modeling. Viable technologies considered during the analysis have been modeled using FLOW. FLOW can normally simulate each scenario by a single flowsheet. Among the features of FLOW, there is the "aggregation" feature that allows the development of a complete flowsheet, using the normal range of unit operations, that can be represented by a single icon. Figure 2 illustrates the FLOW representation of the ORR Toxic Substance Control Act (TSCA) incinerator and the aggregation feature that illustrates what is behind the primary chamber icon. The magnifying glass indicates that the icon has a second level of detail that can be accessed through FLOW. The system allows up to ten levels in depth. Figure 1 shows that the secondary chamber is simulated by a sequence of basic operations such as reactors, heat exchangers, mixers, icons that calculate the quantities of air and fuel, splitters, etc.

Cost Modeling. FLOW's cost tool uses a methodology based on an Idaho National Engineering Laboratory (INEL) study. ${ }^{2}$ Additional data were obtained from a study published by Los Alamos National Laboratory (LANL). ${ }^{3}$ With the INEL cost method, the life-cycle cost for each facility is comprised of six components:

1. research and development,

2. demonstration,

3. facility construction,

4. startup capital (conceptual design, safety, National Environmental Policy Act (NEPA) permitting, preparation for operations, and project management),

5. operations and maintenance, and

6. decontamination and decommissioning.

INEL developed costs for small, medium, and large facilities of each type. Facilities are assumed to operate $24 \mathrm{~h} / \mathrm{d}, 240 \mathrm{~d} /$ year, for 20 years at $70 \%$ availability. In FLOW, costs are grouped into five components:

1. preoperation (INEL component No. $1+$ No. 2 ),

2. construction (INEL component No. 3 + No. 4),

3. operations and maintenance (INEL component No. 5),

4. decontamination and decommissioning (INEL component No. 6), and

5. transportation.

Risk Modeling. The methodology to evaluate risk was developed with the assistance of the ORNL Risk Analysis Section. The methodology uses unit risk factors and procedures for computing atmospheric risk that consider emission rate, unit concentration (Chi/Q), and surrounding population. The unit-risk factor approach uses unit emissions and assumptions for various stack parameters, installation-specific wind conditions, and population data (1990 census) for the site to calculate unit concentrations, or doses. This approach is consistent with that used by DOE in a national programmatic environmental impact study, to which the Risk Analysis Section provided major support.

Risk calculations are based on long-term effects from radiological and chemical sources. The risk model does not take into account acute occupational hazards. Contaminant concentrations are essential for calculating risk. The contaminant concentrations used for this study are sampled from estimates provided by the analysis team. Although the relative risk provides a useful ranking criterion, the absolute values are not reliable due to limitations in the contaminant data and the risk model.

Evaluation Criteria. This section addresses the problem of selecting mixed waste management technologies from a suite of alternatives. In general terms, once the scenarios that include specific technologies are obtained, a ranking procedure follows which indicates an order of preference. Mixed waste management is a multicriteria decision problem. Multicriteria analysis is based on the premise that the outcomes of the various decision criteria need not necessarily be transformed into monetary units in order to arrive at a comprehensive comparison of different project outcomes. Other elements 
besides the traditional monetary evaluation methods, such as social cost-benefit analysis and costeffectiveness analysis, must be taken into consideration-particularly when public concern is involved in the decision-making process. Management and state officials participated in determining the number, the nature, and the priority of the criteria which must be in place to perform an appropriate scenario evaluation.

Adequate performance by both the treatment process and the waste form it produces are criteria to which all interested parties assign a high importance. Performance decision criteria can include: ${ }^{4}$

- Waste treatment capacity

- Production rates

- Plant availability

- Plant maintainability

- Volume reduction

- Contaminant concentrations

- Secondary waste and effluent generation

- Waste-form activity

- Waste-form stability

- Waste-form contaminant release characteristics

In addition, the performance criteria should be quantitative and relevant to regulations and health, safety, and environmental (HS\&E) goals. There are two suggested ways to evaluate the decision criteria elements. The first mechanism is based on determining numerical values for these elements from straightforward formulas. The second mechanism is based on determining figures of merit for these elements.

Once the scenarios that include specific technologies are defined and performance and other evaluation factors are predicted, a ranking procedure follows which indicates an order of preference. This gives the decision maker a basis for an informed decision. The criteria selected for use reflect the values of the stakeholders - what the stakeholders believe to be important. The weights selected are indicative of the relative importance of the each criterion to the others.

The ranking mechanism consists of a simple operation in which the individual criteria scores for each treatment scenario, multiplied by the agreed-to weighing factors, are summed. The sums for the treatment scenarios for each waste are then ranked. The rankings produced indicate the preference of each technology option based on stakeholder values as embodied in the evaluation criteria. ${ }^{5}$

\section{Integration of the Systems Analysis Elements}

To implement the systems model, the many factors that can influence the selection of a waste management scenario must be integrated together to form a clear and logical decision process for comparing one scenario to another. A representation of this systems model is shown in Fig. 2.

To perform the analysis, each scenario is represented by a set of independent process models linked together to form an overall model of each scenario. These models require other data such as costing functions, transportation distances and requirements, and risk estimates. The different elements to be considered in the analysis methodology are linked sequentially in such a manner that the information flows from waste sources to final disposal. Waste characteristics such as quantity, chemical analysis, and location are stored in data bases. Waste treatment technologies available in the form of flow sheets that can be accessed directly by FLOW. Information that is stored in data bases includes: (1) costestimating routines, (2) risk-estimating routines, (3) performance calculations, (4) disposal options and their WACs, and (5) the results of the analysis.

FLOW performs the linking of individual flowsheets into a sequence of operations, as well as other functions required to construct, execute, and evaluate scenarios. The costs of the scenario are broken down into R\&D, construction, O\&M, and D\&D. Risk can be analyzed in terms of both normal operational risk and accident risk for both radiological and toxic contaminants, although for the studies to date, only normal operational risk was analyzed. 
FLOW accesses flow sheet information for the selected technology (previously created using FLOW) one case at a time and calculates performance, cost, and risk. Disposal information, including WACs provided by different installations that receive waste around the country, is used in the analysis to determine if secondary treatment of any of the streams from the proposed processes is required .

It is important to note that this systems analysis methodology is based on order-of-magnitude approach to modeling. Hence, some parameters used by different models may require prior analysis of uncertainties to determine a range of values for those parameters that is satisfactory for the simulation. This uncertainty analysis can be performed within FLOW.

Figure 3 illustrates the flow of information in the analysis. From the list of scenarios, one case is selected. Each scenario is associated with specific waste characterization data. The simulation is performed by FLOW on a specific technology or technology train, which also is defined by the scenario. Results are stored for later use by a performance analysis module in which secondary waste, final waste form, cost, risk, and disposal parameters are analyzed.

Included in the simulation is a comparison of the characteristics of the final waste with the disposal option WACs. The results of this comparison are stored in data bases, along with information produced in other stages of the analysis for this scenario. A ranking mechanism to prioritize scenario options is then applied.

\section{APPLICATION OF THE METHODOLOGY}

The systems analysis methodology presented in the previous sections has been applied to several treatment alternative studies at ORNL. One of the application cases provided the engineering systems analysis needed to formulate the ORR draft site treatment plan (DSTP) for selected waste streams. The remainder of this paper describes this case.

\section{Evaluation of Treatment Options in Development of the ORR DSTP}

The waste groupings and storage locations considered in this study were:

1. Disposal area remedial action (DARA) soils located at Storage Area 60, Y-12 Plant;

2. Central Neutralization Facility (CNF) sludge located at the K-25 Site; and

3. West End Treatment Facility (WETF) sludge stored in the WETF tanks at Y-12.

The treatment options and locations considered were:

(a) The TSCA incinerator at K-25-using grout, sulfur polymer, or vitrification options for stabilization of the ash produced;

(b) A plasma arc located at K-25-using grout, sulfur polymerization, or vitrification options for the stabilization of the ash produced;

(c) A plasma arc located at $\mathrm{K}-25$ - using recycle of the ash produced to the plasma arc;

(d) Low-temperature thermal treatment of the wastes followed by grouting, sulfur polymerization, or vitrification of the dried solids. This facility was assumed to be located at the Y-12 Site; and

(e) Grouting.

As a secondary treatment, the grout and polymer facilities were co-sited with the primary treatment facilities. For cost estimation, Plasma Arc Treatment was assumed to be innovative and a new facility, and kiln treatment (TSCA incinerator) was assumed to be an existing facility. All other treatments were assumed to be new but, not innovative facilities.

The only disposal site considered in this analysis was the Envirocare of Utah site in Clive, Utah. The evaluation criteria used in this study were volume reduction, risk to employees, risk to the public, quality of the final waste form, schedule, reliability/availability/maintainability (RAM), and operability. Table 1 shows the weighting factors given to the evaluation criteria.

The kiln followed by grout treatment had the lowest risk (highest evaluation score) both for on and off site and was near the highest score in every criteria but waste form and operability. The low 
temperature thermal desorption followed by a grout treatment was high scorer in technical risk and consistently scored second or third in the other criteria, except for waste form.

Incineration followed by solidification of the ash by grouting resulted in the highest (most favorable) overall weighted scores, for all three waste streams. Treatment by low temperature thermal desorption followed by grouting was the second highest scoring process train for all three wastes streams. The plasma arc process as a stand alone treatment received the third highest score for treatment of CNF sludge.

\section{CONCLUSIONS}

The methodology developed to analyze and select mixed waste treatment alternatives has proven to be useful in the three cases studied to date. The concept of systems analysis applied to this type of problems allows a global view during the sometimes difficult decision-making process. FLOW, the modeling work-horse of this methodology, has been demonstrated to be a flexible, simple, rapid, and portable tool for top-level analysis of mixed waste treatment scenarios. Scenarios are easily developed and, if necessary, rapidly modified. Risk and cost tools developed at ORNL and other national laboratories have been successfully integrated into FLOW decreasing the duplication of efforts across the DOE complex.

The intrinsic analysis involved in the methodology has been accepted as a viable tool by Tennessee officials, and it is expected to be applicable in other studies that will help the DOE activities in conjunction with state acceptability. The application of systems analysis in mixed waste treatment problems have proven their efficacy. There is, however, room for improvement in the methodology and in the tools used in the course of the analysis.

Evaluation criteria are selected to reflect stakeholder values. A different group of stakeholders may have a different perception of the attributes influencing a decision process, and thus produce a different outcome in the ranking of the alternatives. In general terms, our evaluations were most influenced by risk and project cost, technical risk, and RAM. It could be beneficial to perform a sensitivity analysis of the dominating factors on the evaluation to determine the impact on the overall rankings of the scenarios. At the same time, it seems appropriate to suggest that an uncertainty analysis be performed on the variables or parameters that are not fully determined at the moment to ascertain the degree of impact in the overall result of the evaluation.

The results produced in these studies may be refined when more accurate information is obtained about technical uncertainties found in some treatment alternative such as the debris washing system, plasma arc, molten salt, and catalytic extraction subsystems. Cost and risk models continue to evolve as interest (by sponsors) in better models increases, and as available methods and data improve. Likewise, technology models will be improved by updating technical performance and cost data as they become available. In addition to the advantages of this methodology enumerated earlier, studies such as these provide valuable information on technology research and development needs, waste characterization requirements, and needed treatability studies. 


\section{REFERENCES}

1. U.S. Department of Energy, Interim Mixed Waste Inventory Report: Waste Streams, Treatment Capacities and Technologies, DOE/NBM-1100, Washington, DC., April 1993.

2. Feizollahi, F. and Shropshire, D., Waste Management Facilities Cost Information Report, EGG-WTD-10443;EG\&G, Idaho National Engineering Laboratory, Idaho Falls, Idaho; 1992; pp 3-90.

3. Barnes-Smith, P. and Booth, S.R., Life Cycle Cost Analysis for the Plasma Arc Furnace, Draft MWIP report, Los Alamos National Laboratory, Los Alamos, New Mexico; 1993.

4. Ferrada, J.J. and Berry, J.B., Multicriteria Decision Methodology for Selecting Technical Alternatives in the Mixed Waste Integrated Program, DOE/MWIP-14; Martin Marietta Energy Systems, Oak Ridge National Laboratory, Oak Ridge, Tennessee; 1993; pp 3-85.

5. Ferrada, J.J.; Hazardous Chemical Waste Management, lst ed.; Garland Publishing, Inc.; New York \& London, 1990; pp 225-251.

6. Ferrada, J.J., Welch, T.D., Nehls, J.W., Osborne-Lee, I.W., Lee, H.L.,Systems Analysis of Oak Ridge Reservation Mixed Waste Treatment Alternatives, ORNL/TM-12842 (draft); Martin Marietta Energy Systems, Oak Ridge National Laboratory, Oak Ridge, Tennessee, 1994. 


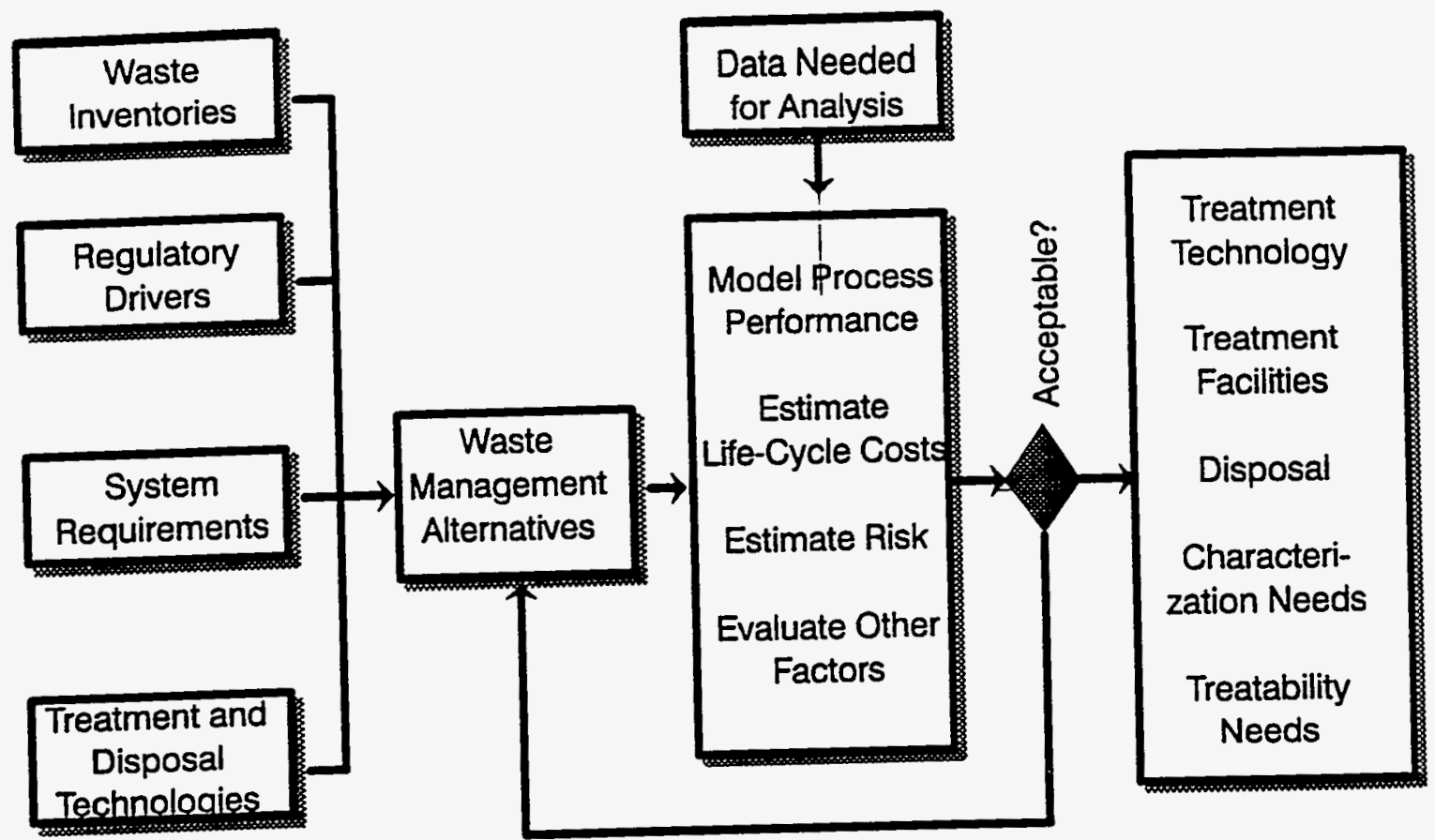

Fig.1. Factors that determine a waste management scenario.

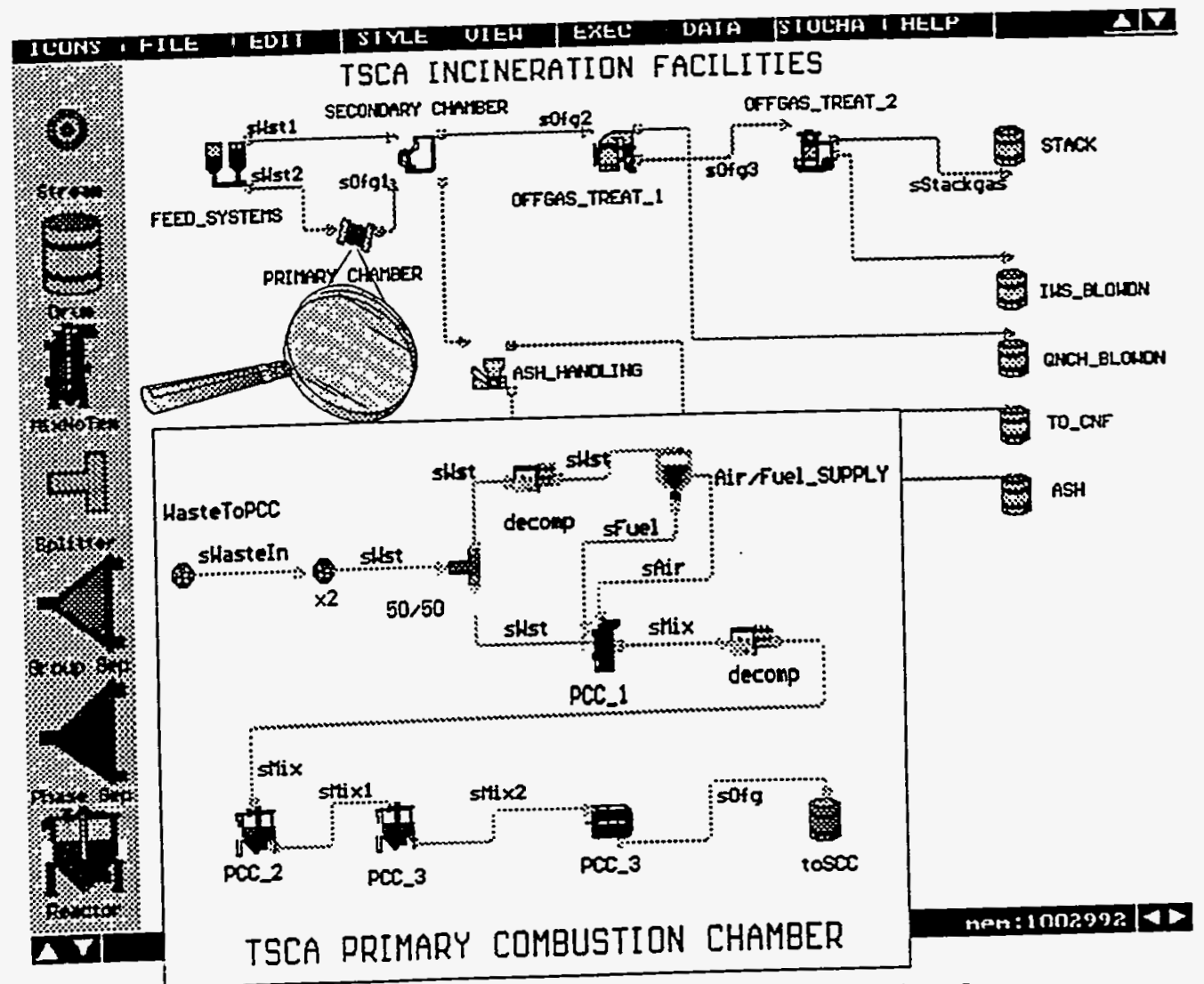

Fig. 2. Representation of FLOW and the aggregation feature. 


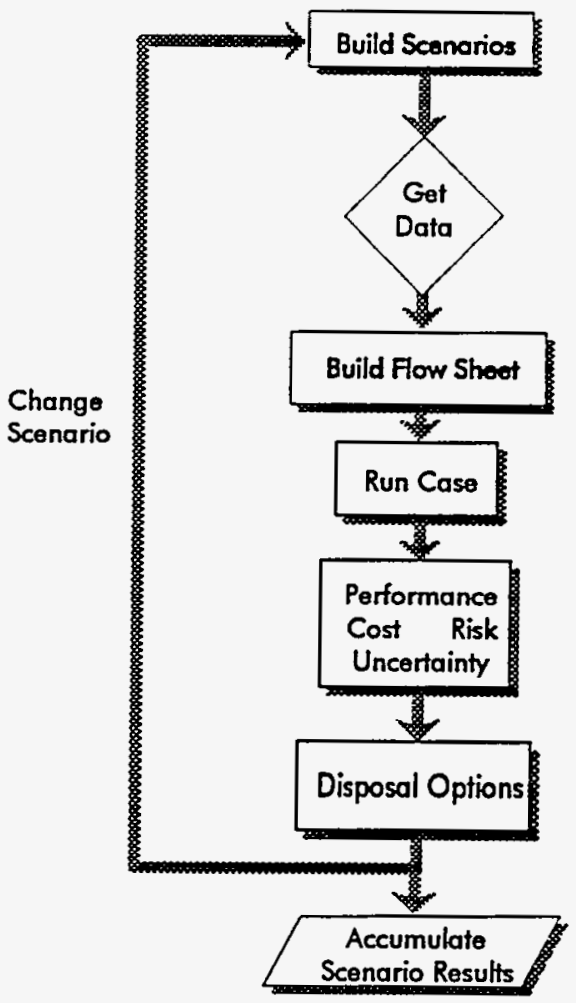

Fig. 3. Flow of information in the systems analysis methodology.

Table 1. Decision analysis criteria and weighting factors.

\begin{tabular}{|l|c|}
\hline \multicolumn{1}{|c|}{ Criteria element } & Weighting factor \\
\hline Volume reduction & 6 \\
\hline Risk (to employee) & 10 \\
\hline Reliability, availability, and maintainability & 4 \\
\hline Schedule & 7 \\
\hline Technical risk & 8 \\
\hline Final waste form & 2 \\
\hline Cost & 8 \\
\hline Operability & 4 \\
\hline Risk (to public and environment) & 10 \\
\hline
\end{tabular}

